\title{
Improved PSO Algorithms in PV System Optimisation
}

\author{
Wafa Hayder, Aicha Abid, Mouna Ben Hamed, and Lasaad Sbita
}

\begin{abstract}
This paper deals with an analysis and implementation of a control method proposed in the maximum power point tracking (MPPT) for photovoltaic systems. The Improved Particle Swarm Optimization (IPSO) algorithm is developed and implemented in Matlab/Simulink environment. Many simulations have been done considering the different system responses as the current, voltage and essentially the power. The efficiency of the proposed MPPT algorithm have been carried out.
\end{abstract}

Index Terms-Maximum Power Point Tracking (MPPT); Particle Swarm Optimization algorithm (PSO); Photovoltaic (PV); optimum duty cycle.

\section{INTRODUCTION}

In recent years, solar energy becomes one of the most popular areas of renewable energy due to intensive energy demand and several advantages related to availability and cleanness environment [1], [2]. Photovoltaic (PV) module arrays is characterized by nonlinear power-voltage $(\mathrm{P}-\mathrm{V})$ that depends on variation in atmospheric conditions such as insolation and temperature [3]. One of the fundamental problems is how to carry out the maximum power point tracking (MPPT). Recently, a number of researches synthesized different methods to resolve the problems related to MPPT controller such as power feedback, incremental conductance, short circuit current, open circuit voltage [4], ripple correlation control (RCC) and perturb and observe methods [5]. These traditional MPPT techniques have low equipment requirement and easy structures. Nevertheless, they have many problems such as oscillations around the operating point and the long time required to achieve MPP. So, it is impossible to track PV module's maximum power under rapidly changing environmental conditions which causes the reducing of the system efficiency. However, the Improved Particle Swarm Optimization (IPSO) was proposed and implemented as controller for enhancing the convergence speed and achieving the MPPT when temperature and/or irradiation change.

The remainder of this paper is organized as follows; the second part represents the fundamental characteristics of the PV system. The third section explains the IPSO algorithm. Section four represents the different obtained simulation results. The five section summarizes and concludes this work.

Published on January 20, 2020.

W. Hayder, Electrical Engineering Department, National Engineering School of Gabes (ENIG), Tunisia.

(e-mail: wafa.hayder@gamil.com)

A. Abid is with the Electrical Engineering Department, National Engineering School of Gabes (ENIG), Tunisia.

(e-mail: aicha.abid@gmail.com)

\section{Characteristic OF The Photovoltaic System}

A PV energy system as illustrated in Fig. 1 is composed of a PV array and a boost converter feeding resistive load.

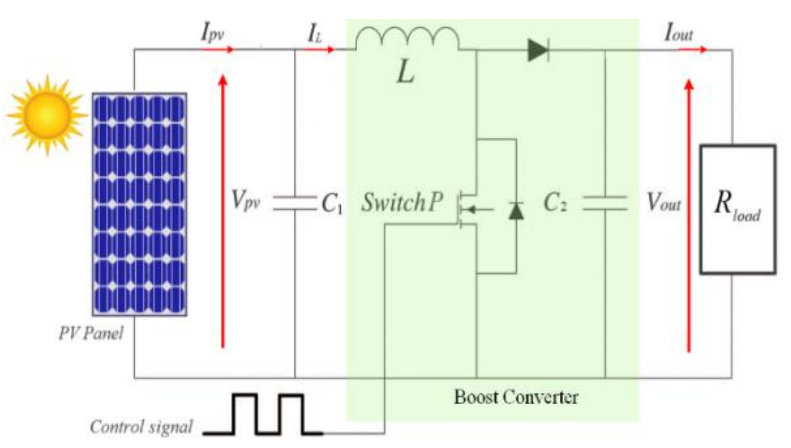

Fig. 1. Equivalent schematic for PV system

\section{A. PV panel modeling}

The current of the PV panel can be expressed as [7]:

$$
I=n_{p} \times I_{s c}-n_{p} \times I_{0} \times\left(e^{\left(\frac{V+I \times R s}{n_{s} \times V_{t}}\right)}-1\right)
$$

The short-circuit current $I_{s c}$ and the junction thermal voltage $V_{t}$ are defined by (Eq.2 and 3).

$$
\begin{gathered}
V_{t}=\frac{n_{s} A k T}{q} \\
I_{s c}=\left(\mathrm{I}_{\mathrm{scSTC}}+\mathrm{ki} \times\left(\mathrm{T}-\mathrm{T}_{\mathrm{STC}}\right)\right) \times \frac{G}{G_{S T C}}
\end{gathered}
$$

where $n_{p}$ is the number of PV cells connected in parallel; ns is the number of the series cells; $I 0$ is the dark saturation current $(A) ; A$ is the diode ideality factor ; $q$ is the charge of the electron $(C) ; T$ is the temperature $(K) ; k$ is the Boltzmann's constant and GSTC is the irradiance under Standard Test Conditions (STC).

To verify the simulations results the BPMSX-120 solar panels has been implemented under Matlab/Simulink on different environmental conditions. The panel electrical parameters are cited in Table 1 [8]. 


\section{TABLE I: BPMSX-120 ELECTRICAL PARAMETERS}

\begin{tabular}{lll} 
Maximum power & $P_{m p}$ & $120 \mathrm{~W}$ \\
Voltage at $P_{m p}$ & $V_{m p}$ & $33.7 \mathrm{~V}$ \\
Current at $P_{m p}$ & $I_{m p}$ & $3.56 \mathrm{~A}$ \\
Short circuit current & $I_{s c S T C}$ & $3.87 \mathrm{~A}$ \\
Open circuit voltage & $V_{\text {ocSTC }}$ & $42.1 \mathrm{~V}$ \\
$\begin{array}{l}\text { Temperature coefficient of } \\
I_{s c S T C}\end{array}$ & $k i$ & $0.065 \% /{ }^{\circ} \mathrm{C}$ \\
$\begin{array}{l}\text { Temperature coefficient of } \\
V_{\text {ocSTC }}\end{array}$ & $k v$ & $-80 \mathrm{mV} /{ }^{\circ} \mathrm{C}$ \\
\hline
\end{tabular}

The output power and current of the PV panel have a nonlinear behavior in function of voltage. The increase in solar radiation causes a slight increase in optimal voltage $\left(V_{m p}\right)$ and augmentation not only in maximum power point $\left(P_{m p}\right)$ but also in optimal current $\left(I_{m p}\right)$ as shown in Fig. 1 and 2.Thus the increase in temperature leads to decrease in $V_{m p}$ and reduction not only in Imp but also in $P_{m p}$ as demonstrated in Fig. 3 and 4. Furthermore, the augmentation in series resistance provides the decreasing in $V_{m p}$ and reduction in Imp and $P_{m p}$ values that are illustrated in Fig. 6 and 7. All these figures show the existence of unique MPP on each P-V curve. In order to find the maximum power generated by PV array, a maximum power point controller must be synthesized.
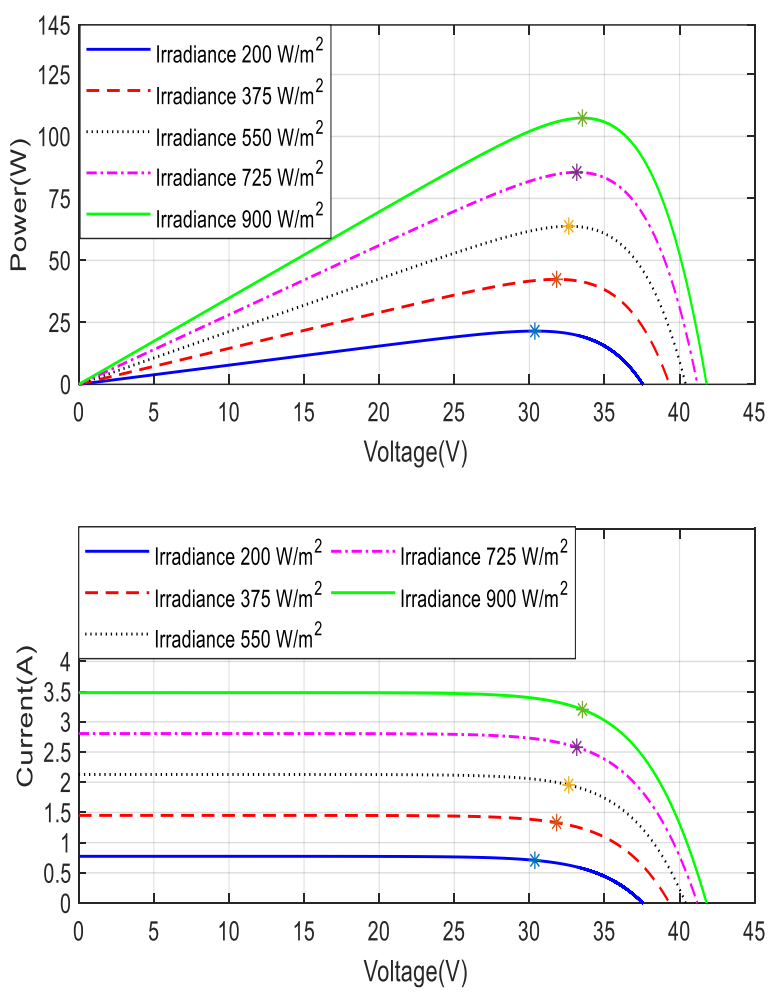

Fig. 2. P-V and I-V curves of the PV panel affected by variable irradiance
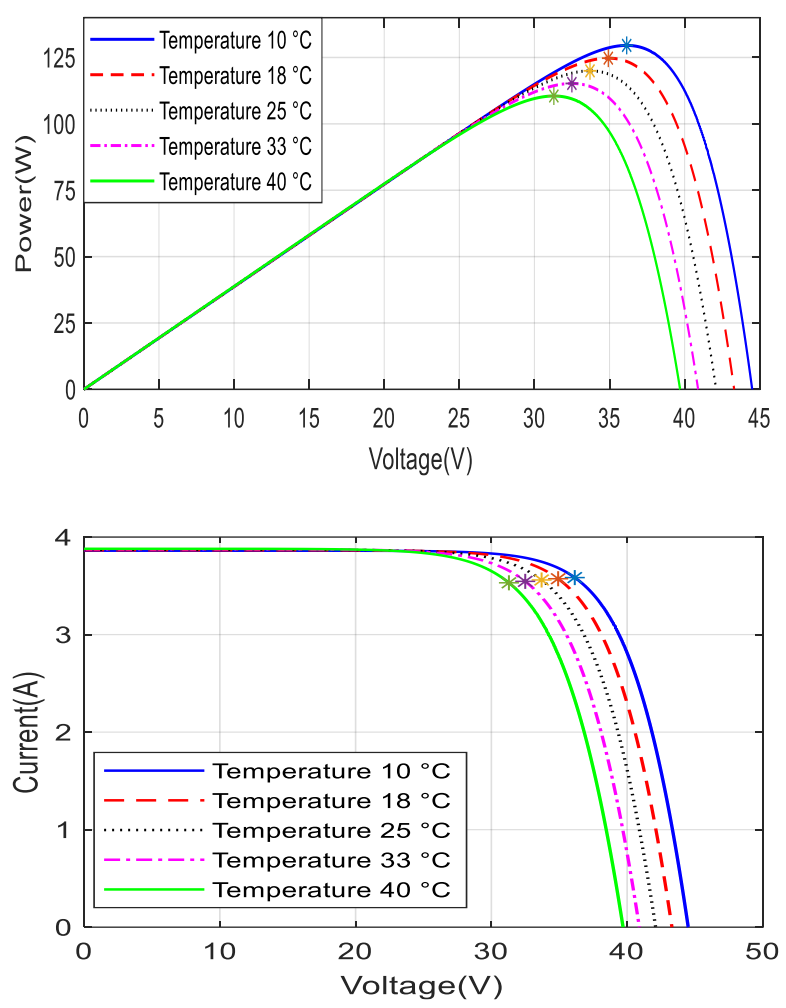

Fig. 3. P-V and I-V curves of the PV panel affected by variable temperature
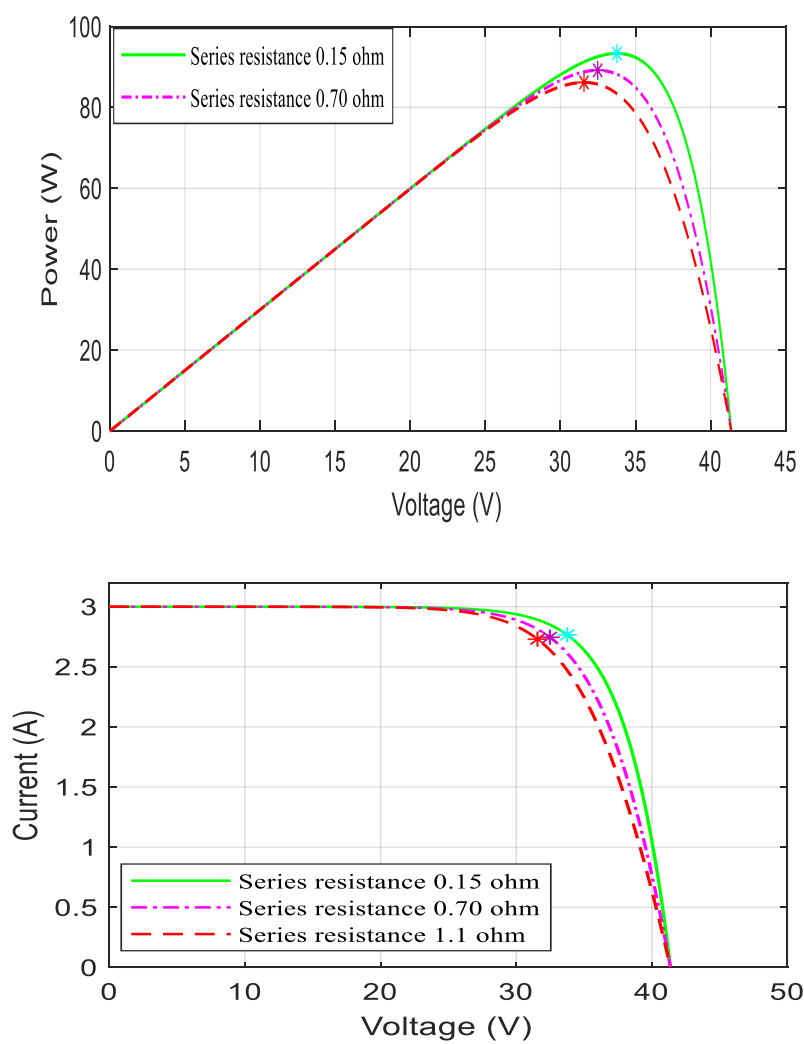

Fig. 4. P-V and I-V curves of the PV panel affected by variable series resistance 


\section{B. Modeling of DC-DC boost converter and design}

The model of the boost converter as shown in Fig. 1 can be expressed as:

$$
\left\{\begin{array}{l}
\frac{d V_{P V}}{d t}=\frac{1}{C_{1}}\left(i_{P V}-i_{L}\right) \\
\frac{d V_{\text {out }}}{d t}=\frac{1}{C_{2}}\left((1-D) i_{L}-\frac{V_{\text {out }}}{R_{\text {load }}}\right) \\
\frac{d i_{L}}{d t}=\frac{1}{L}\left(V_{P V}-(1-D) V_{\text {out }}\right)
\end{array}\right.
$$

The DC-DC boost converter is used to achieve the MPP by adjusting its duty cycle $D(0<D<1)$. This later is generated by an adequate MPPT controller that is PSO algorithm.

\section{IMPROVED PARTICLE SWARM OPTIMIZATION BASED MPPT}

The learning process of particles is based on two rules: attracted towards the global best position discovered by others (social influence) and drawn towards its local best promising position (cognition influence) [9]-[12]. The position of each particle will be evaluated by a fitness function. In this work, the fitness function Di is defined as the actual duty cycle while velocity $\Delta D_{i}$ shows the perturbation in the present duty cycle. The global $G_{b e s t}$ and local $P_{b e s t i}$ best positions are defined by how much power generated by a specific operating duty cycle. The highest power generated is the best.

During the searching process (iterative process), the velocity and position of each particle is updated based on the inertia weight $\mathrm{w}$, random numbers $\left\{r_{1}, r_{2}\right\} \in[0 . .1]$, cognitive component $\mathrm{c} 1$ and social component $\mathrm{c} 2$, as shown in (5) and (6):

$$
\begin{gathered}
D_{i}^{k+1}=D_{i}^{k}+\Delta D_{i}^{k} \\
\Delta D_{i}^{k+1}=w \times \Delta D_{i}^{k}+r_{1} c_{1}\left(P_{\text {besti }}-D_{i}^{k}\right)+r_{2} c_{2}\left(G_{\text {best }}-D_{i}^{k}\right)(6)
\end{gathered}
$$

To illustrate the application of the IPSO algorithm in tracking the MPP using the direct control technique, first a solution vector of duty cycles with $\mathrm{Np}$ particles is determined, i.e.

$$
D_{i} \in\left[K_{(i-1)}, K_{i}[, 1 \leq i \leq N p\right.
$$

Where: $\left\{\begin{array}{l}K_{0}=0 \\ K_{i}=\left\lfloor\frac{i}{N p}\right\rfloor \text { with } 1 \leq \mathrm{i} \leq \mathrm{Np}\end{array}\right.$

In order to complete properly the optimal duty cycle to achieve the MPPT, the following flowchart has been applied.

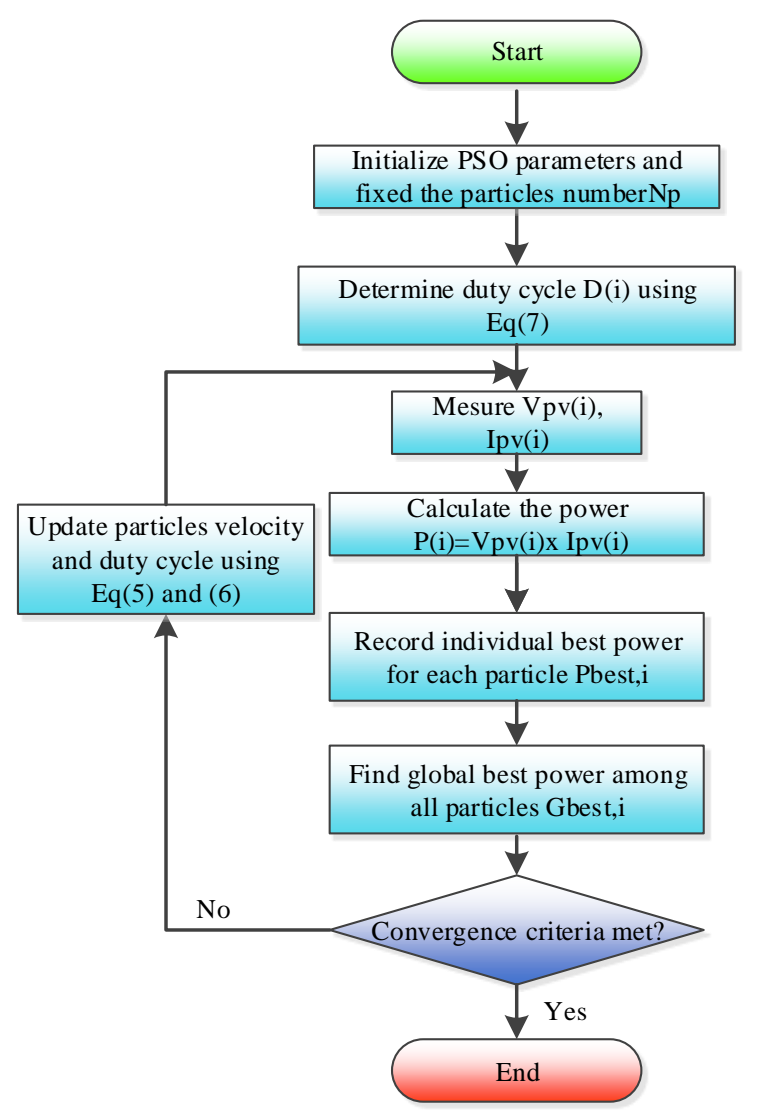

Fig. 5. Flowchart of IPSO-based MPPT algorithm.

\section{RESULTS AND DISCUSSION}

To approve the effectiveness of IPSO, simulations are executed under Matlab/Simulink environment in different conditions: change in irradiance (Fig.10.(a)), temperature (Fig.11.(a)) and series resistance (Fig.12.(a)) for three particles. The application of IPSO algorithm presented in Fig.9, guarantee the convergence of the control signals, feeding the DC-DC Boost converter, to the optimal duty cycle in every variation of irradiance, temperature and series resistance as shown in Fig.10. (b), Fig.11. (b) and Fig.12. (b), respectively. The fluctuation of the duty cycle is followed by not only the oscillation of voltage, as shown in Fig.10. (c), Fig.11. (c) and Fig.12. (c), but also the variation of the PV power, as illustrated in Fig.10. (d), Fig.11. (d) and Fig.12. (d).

These figures insisted that the convergence of duty cycle leads to stabilize the voltage and the power at one value, $V_{\text {opt }}$ and $P_{\text {opt }}$, during every change. For that, IPSO strategy seems to be a powerful algorithm to reach the MPP with high rapidity and stability. 


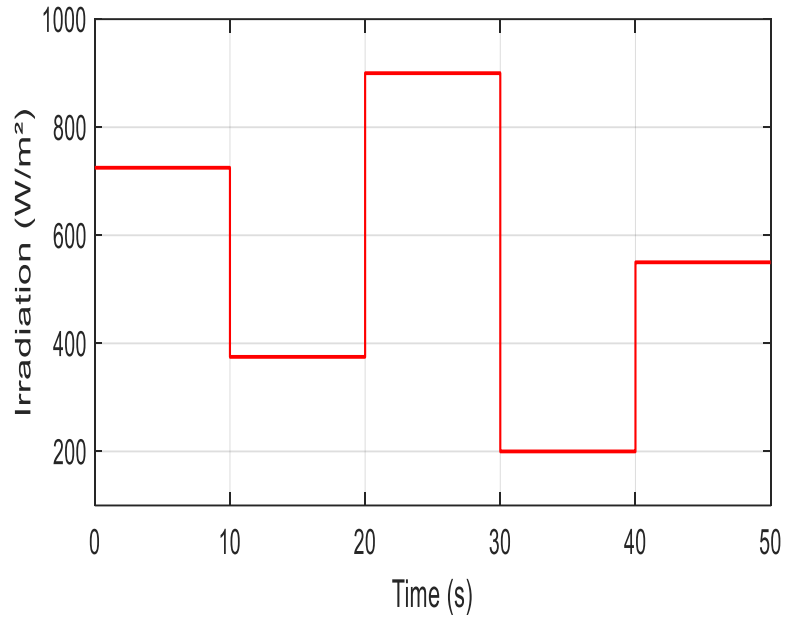

(a)

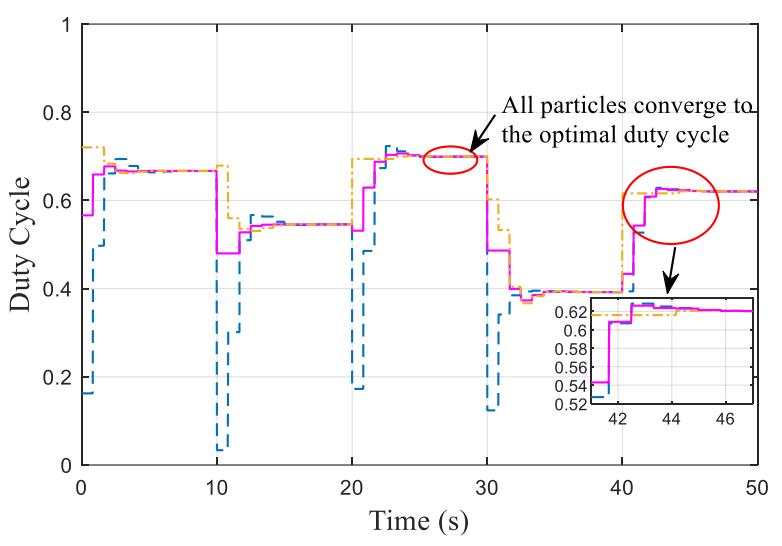

(b)

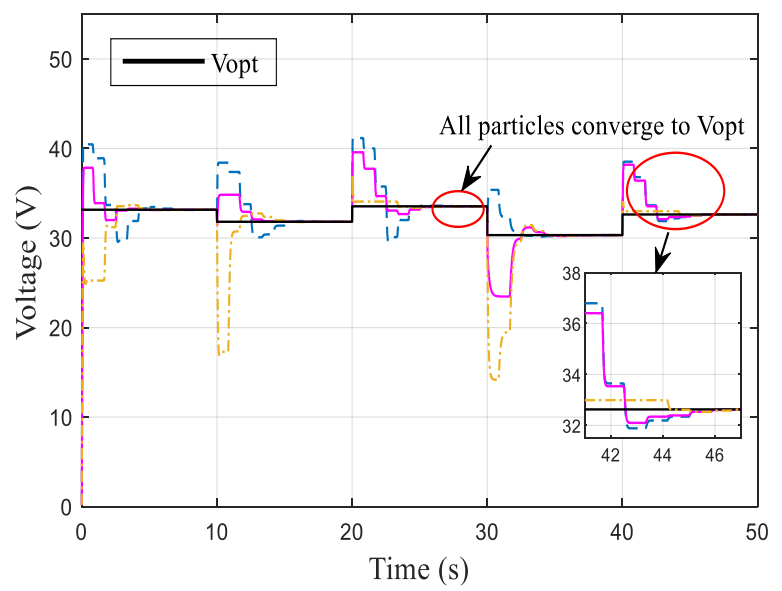

(c)

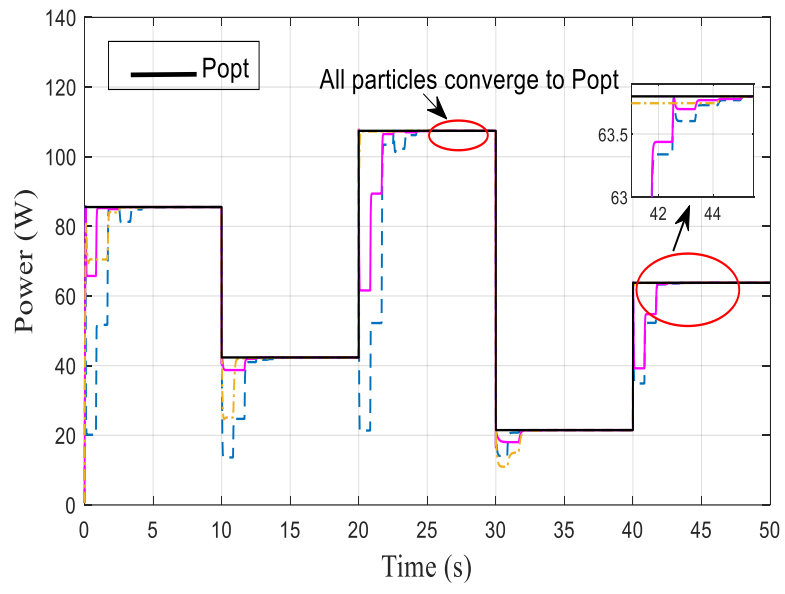

(d)

Fig. 6. Simulation results under radiation variation: (a) Irradiance profile, (b) Duty cycle given by PSO algorithm, (c) Voltage under irradiance change and (d) Power under irradiance change.

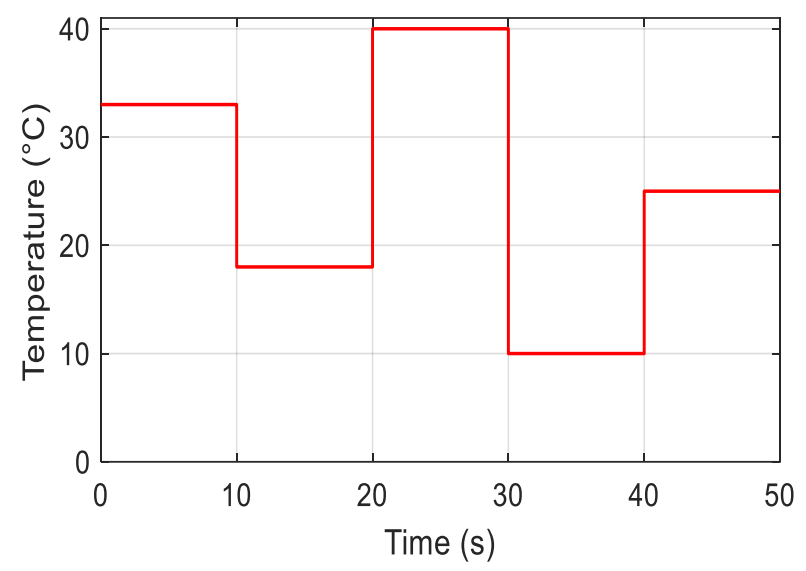

(a)

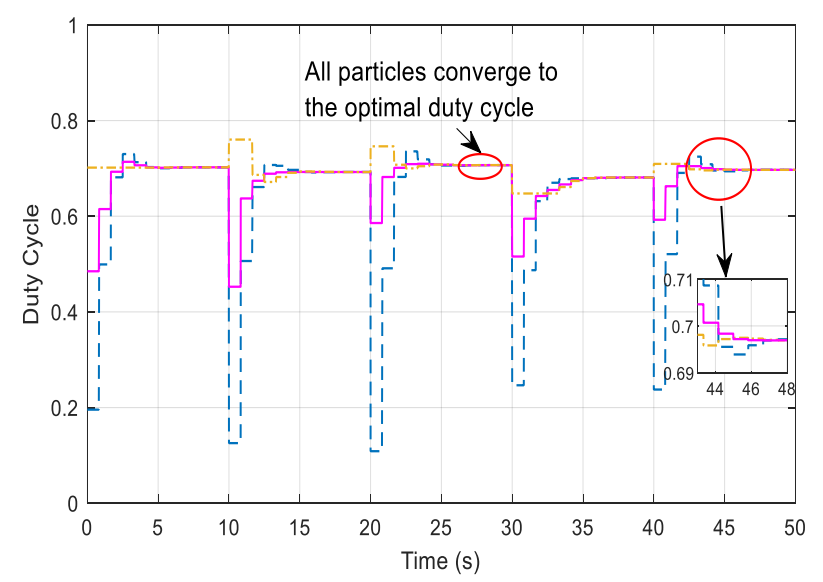

(b) 


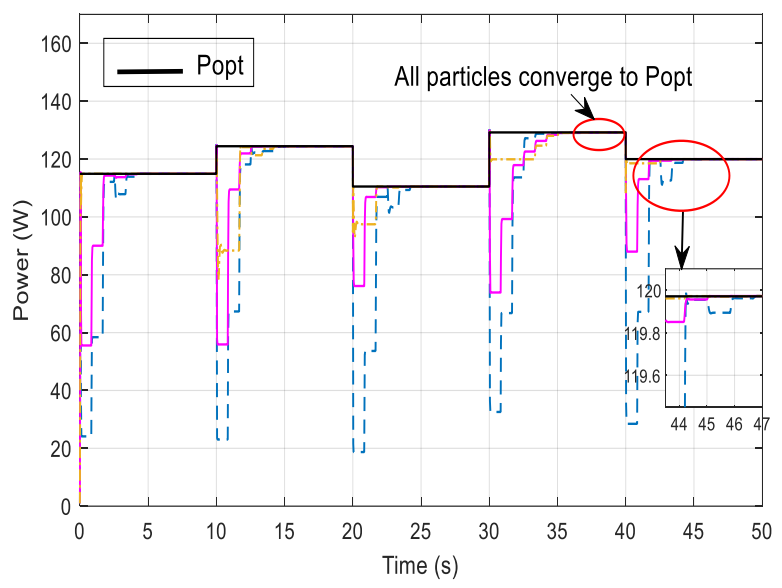

(c)

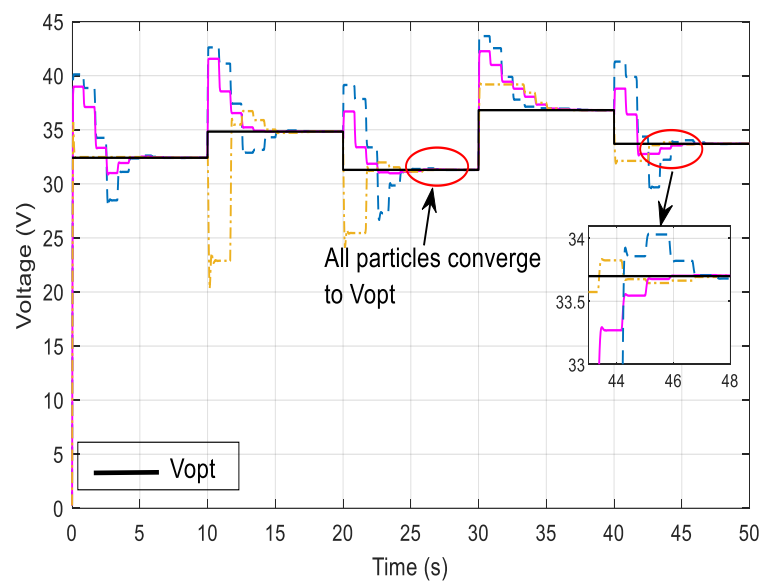

(d)

Fig. 7. Simulation results under temperature variation: (a) Temperature profile, (b) Duty cycle under temperature change, (c) Power under temperature change and (d) Voltage under temperature change

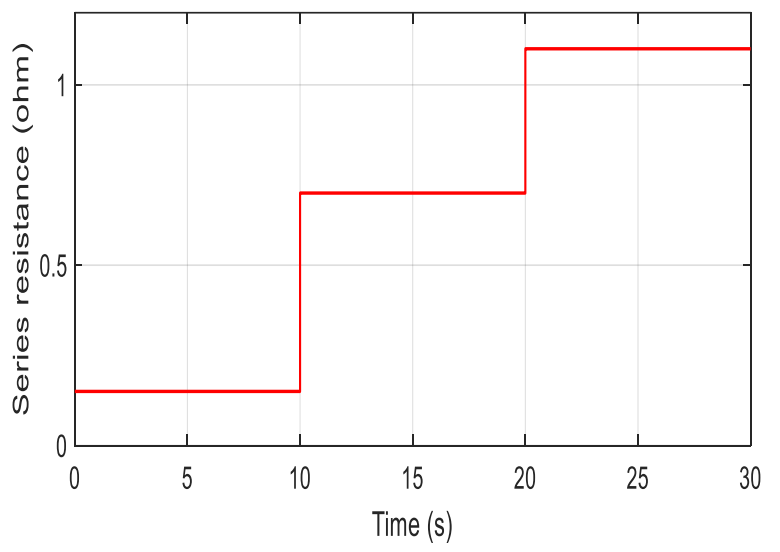

(a)

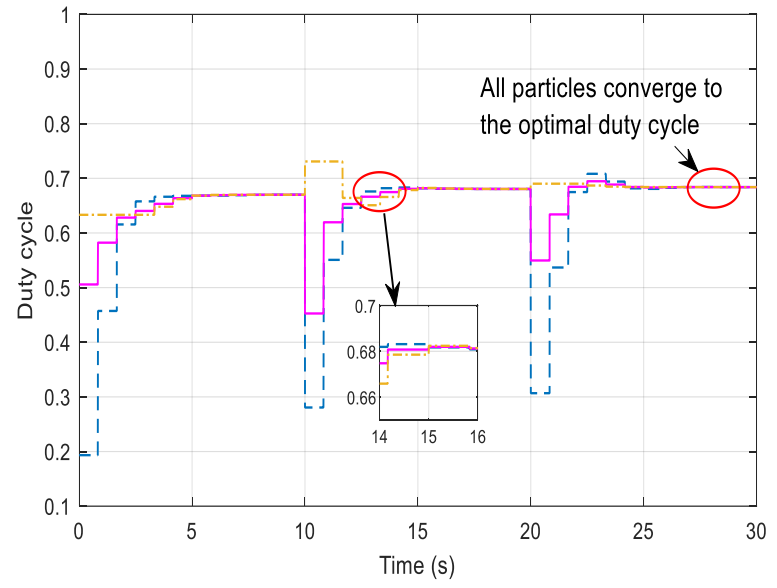

(b)

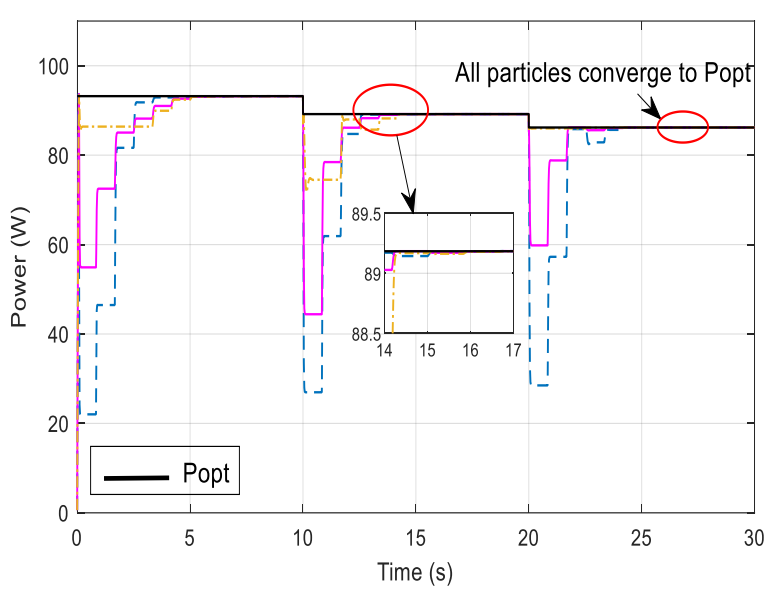

(c)

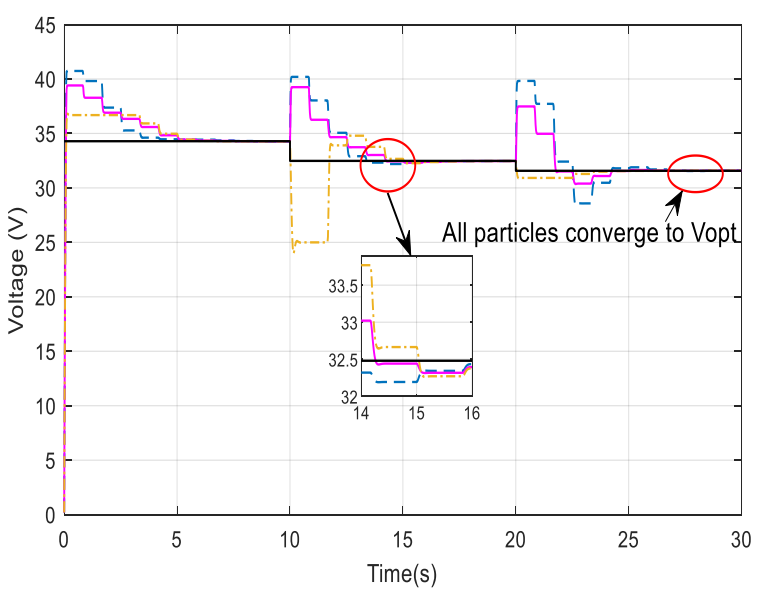

(d)

Fig. 8. Simulation results under series resistance variation: (a) Series resistance profile, (b) Duty cycle under series resistance change,

(c)Power under series resistance change and (d) Voltage under series resistance change.

\section{CONCLUSION}

In this paper, an enhanced algorithm for maximize the PV system power point via IPSO controller feeding a DC-DC boost converter is implemented. Based on successive iteration, IPSO converge the particles to the leader swarm particle recognized by optimal duty cycle which moves the 
outputs PV system to the MPP. Furthermore the IPSO algorithm guarantee the rapidity and the high accuracy of the PV system. To consolidate these performances, the proposed IPSO will be tested and validated under shading.

\section{REFERENCES}

[1] K. Ishaque and Z. Salam, "A review of maximum power point tracking techniques of PV system for uniform insolation and partial shading condition," Renew. Sustain. Energy Rev., vol. 19, pp. 475-488, 2013.

[2] F. Spertino, J. Ahmad, A. Ciocia, and P. Di Leo, "A technique for tracking the global maximum power point of photovoltaic arrays under partial shading conditions," 2015 IEEE 6th Int. Symp. Power Electron. Distrib. Gener. Syst. PEDG 2015, vol. 00, no. c, 2015.

[3] A. Al Nabulsi, R. Dhaouadi, and S. Member, "Nabulsi, Dhaouadi, Member - 2011 - Efficiency Optimization of a DSP-Based Standalone PV System using Fuzzy Logic and Dual-MPPT Controlannotated.pdf," vol. 8, no. 3, pp. 1-12, 2012.

[4] S. Messalti, A. Harrag, and A. Loukriz, "A new variable step size neural networks MPPT controller: Review, simulation and hardware implementation," Renew. Sustain. Energy Rev., vol. 68, no. September 2016, pp. 221-233, 2017.

[5] N. Femia, G. Petrone, G. Spagnuolo, and M. Vitelli, "Optimization of perturb and observe maximum power point tracking method," IEEE Trans. Power Electron., vol. 20, no. 4, pp. 963-973, 2005.

[6] Z. Cheng, H. Zhou, and H. Yang, "Research on MPPT control of PV system based on PSO algorithm," 2010 Chinese Control Decis. Conf. CCDC 2010, pp. 887-892, 2010.

[7] K. Ishaque, Z. Salam, M. Amjad, and S. Mekhilef, "An improved particle swarm optimization (PSO)-based MPPT for PV with reduced steady-state oscillation," IEEE Trans. Power Electron., vol. 27, no. 8, pp. 3627-3638, 2012.

[8] P. Rodriguez, D. Sera, R. Teodorescu, and P. Rodriguez, "PV Panel Model Based on Datasheet Values PV panel model based on datasheet values," no. March, pp. 2392-2396, 2014.

[9] Y. Soufi, M. Bechouat, and S. Kahla, "Fuzzy-PSO controller design for maximum power point tracking in photovoltaic system," Int. J. Hydrogen Energy, vol. 42, no. 13, pp. 8680-8688, 2017.

[10] D. J. Coyle et al., "Life prediction for CIGS solar modules part 2," Prog. Photovoltaics, no. October 2011, pp. 156-172, 2013.

[11] M. Miyatake, M. Veerachary, F. Toriumi, N. Fujii, and H. Ko, "Maximum power point tracking of multiple photovoltaic arrays: A PSO approach,” IEEE Trans. Aerosp. Electron. Syst., vol. 47, no. 1, pp. 367-380, 2011.

[12] G. Dileep and S. N. Singh, "An improved particle swarm optimization based maximum power point tracking algorithm for PV system operating under partial shading conditions," Sol. Energy, vol. 158, no. September, pp. 1006-1015, 2017.

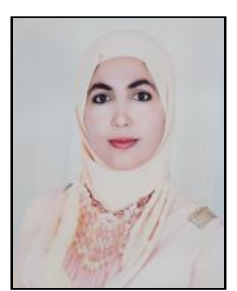

W. Hayder received her B.S. degree in ElectricAutomatic engineering and M.Sc. degree in Automatic and Intelligent Techniques from National Engineering School of Gabes (ENIG), Tunisia in 2009 and 2010, respectively. She is currently a Ph.D. Student with the Department of Electrical Engineering, at the same School. Her current research interests include control, modelling, power electronics and maximum power point tracking (MPPT) of PV arrays.

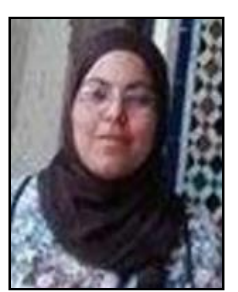

A. Abid obtained the Master degree on September 222006 in and PHD degree on Marsh 042009 in automatic and intelligent techniques from National engineering School of Gabes. Her fields of interest include power electronics, machine drives, automatic control, modelling, observation, identification, fault detection, localization and Isolation.

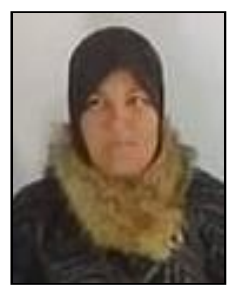

M. Benhamed obtained the Master degree on September 222006 in and $\mathrm{PhD}$ degree on Marsh 042009 in automatic and intelligent techniques from National engineering School of Gabes. She works actually as a professor at the High Institute of Industrial Systems of Gabes (ISSIG) of GabesTunisia. Her fields of interest include power electronics, machine drives, automatic control, modelling, observation, identification, fault detection, localization and Isolation

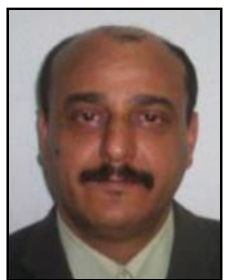

L. Sbita obtained the doctorate thesis on July 1997 in Electrical engineering from ESSTT of Tunis, Tunisia. He works as Professor at electricalautomatic genius department of the National Engineering School of Gabes, Tunisia. He received the "Habilitation Diriger des Recherches" (HDR) from the National School of Sfax, Tunisia in Marsh O8 2008. His fields of interest include power electronics, machine drives, automatic control, modelling, observation and identification. 